\title{
Conservative Management of Acute Lumbar Disc Herniation
}

\section{Soleimani ${ }^{1}$, Owlia MB ${ }^{1 *}$, Dahaj AA ${ }^{2}$, Lotfi $\mathbf{M}^{3}$, Dehghan A $^{1}$ and Mehrpoor $\mathbf{G}^{4}$}

${ }^{1}$ Rheumatologist, Shahid Sadoughi University of Medical Sciences, Yazd, Iran

${ }^{2}$ Resident of surgery Mashhad University of Medical Sciences, Mashhad, Iran

${ }^{3}$ Shahid Sadoughi University of Medical Sciences, Yazd, Iran

${ }^{4}$ Internist, Alborz University of Medical Sciences, Karaj, Iran

\begin{abstract}
Background: Low back pain (LBP) due to acute disc herniation is a common disease bellow the age 45 years of age. Nowadays several types of treatment modalities used to manage these patients. The economic burden of LBP is heavy. LBP rank fifth among category of diseases in cost of hospital care. LBP has higher indirect costs due to absenteeism from work and disability than any other disease. This study was performed to assess the clinical outcomes of non-surgically treatment of LBP patients after six months follow up.
\end{abstract}

Material \& methods: Present prospective study was performed among 50 lumbar radicular patients with clinical signs and symptoms of acute lumbar disc herniation (less than three months). Their diagnosis was confirmed by Magnetic Resonance Imaging (MRI) study. The patties were treated conservatively during six months. Study outcome variables were pain and disability that were assessed by Visual Analog Scale (VAS) and Oswestry Disability Questionnaire (ODQ).

Results: Twenty $(40 \%)$ female and $30(60 \%)$ male were participated in the study. During the follow up period, five (10\%) patients (four male) were referred to neurosurgeon due to poor response to conservative treatment and motor weakness. Pain of patients according to VAS after six months conservative treatment significantly improved than initial evaluation of patients $(3.11 \pm 1.83,7.1 \pm 1.43 \mathrm{P}=0.00)$. Disability score of patients significantly improved with conservative treatment in follow up period $(25.82 \pm 16.92,53.66 \pm 17.66 ; \mathrm{P}=0.00)$.

Conclusion: Results of our study showed that conservative treatment in patients with acute lumbar disc herniation causes significant pain relief and disability improvement without any notable side effect.

Keywords: Low back pain; Lumbar radicular pain; Disc herniation; Conservative treatment

\section{Introduction}

Low Back Pain (LBP) is a common-condition younger than the 45 years of age. The estimated annual LBP incidence in Western countries is five cases per 1000 adults [1]. The economic burden of lumbar-spine disorders is heavy. This disorder ranks fifth among category of diseases for hospital care cost and has higher costs due to absenteeism from work and disability than any other disease [2]. LBP due to acute lumbar disc herniation is a common disorder at the ages of $44-50$ years. It is characterized by radiating pain in the area of the leg typically served by one nerve root in the lumbar or sacral spine $[1,2]$. Several conservative and surgical modalities were applied for these patients. Cauda equina syndrome was considered as the single absolute indication for surgery in a LBP patient [3-5]. Ninthly and ninthly five percents of acute disc herniation patients were improved during two months with conservative treatment such as bed rest, life style modification, medication, back support, exercise, manipulation, physical therapy And epidural steroid injection [3-7]

Previous studies reported that conservative treatment such as nonsteroidal anti-inflammatory drugs cause pain relief in patients with disc herniation $[8,9]$. Other drugs such as muscle relaxant might be useful in acute low back pain [9]. Some reports showed that oral steroid did not have useful impacts on acute lumbar disc herniation [8,9].

Epidural injection is one of the alternative treatment modalities for patients who did not respond to conservative treatment or have contraindication for surgery [9-12]. This study was performed to assess the clinical outcomes of non-surgically treated LBP patients after six months follow up.

\section{Material and Methods}

Present prospective study was performed among 50 patients with clinical signs and symptoms of acute lumbar disc herniation(less than three months symptoms) who confirmed by MRI. Our subjects then were referred to rheumatology clinic of Shahid Sadoughi hospital, Yazd, Iran. This study was approved by ethical board and fully supported by Shahid Sadoughi University of Medical Sciences.

\section{Study samples}

Our sampling method was consecutive sampling and also written informed consent was obtained from all patients. Patients who had symptoms and signs of radicular pain in L5 or S1 territory level were assessed by neurologic and lumbar movement examination, detection of muscle force and Straight Leg Raising test (SLR). MRI was done for all patients and if they had disc herniation without exclusion criteria were included in this study. The exclusion criteria were: degenerative or spinal canal stenosis, tumor, trauma, infection, spondilolysthesis or signs and symptoms of neurologic deficit.

\section{Study design}

All patients were visited by rheumatologist; and MRI imaging studies were used for diagnosis confirmation. An independent

${ }^{*}$ Corresponding author: Dr. Mohammad Bagher Owlia, M.D, Rheumatologist, Shahid Sadoughi University of Medical Sciences, Shahid Sadoughi hospital, Rheumatology Department, Yazd, Iran, Tel: +98 351 8224001; Fax: +98 351 8224100; E-mail: bagherowlia@gmail.com

Received December 11, 2012; Accepted March 22, 2013; Published March 22 , 2013

Citation: Soleimani H, Owlia MB, Dahaj AA, Lotfi M, Dehghan A, et al. (2013) Conservative Management of Acute Lumbar Disc Herniation. J Spine 2: 134. doi:10.4172/2165-7939.1000134

Copyright: (c) 2013 Soleimani $\mathrm{H}$, et al. This is an open-access article distributed under the terms of the Creative Commons Attribution License, which permits unrestricted use, distribution, and reproduction in any medium, provided the original author and source are credited. 
research physician verified symptoms and signs of selected patients at the time of enrollment. Patients with acute lumbar disc herniation were included. Radiculopathy and disc herniation in our subjects were confirmed by MRI. Complete clinical evaluations consist of SLR test, muscle strength, reflexes (Patellar and Achilles), sensory changes, the Oswestry Disability Questionnaire, 100-mm visual-analogue scale were performed for included patients at the initial time and after six months follow up.

\section{Conservative treatment}

Conservative treatments such as life style modification, bed rest, drug therapy with non steroid anti inflammatory drugs, muscle relaxant, systemic injection of corticosteroids, epidural injection, physiotherapy and three cyclic anti depressants (TCAs) depending on each patient's situation were prescribed to the patients after initial evaluation.

\section{Statistical analysis}

All data were analyzed by non parametric tests such as MannWhitney and Wilcoxon test after entering study data to the computer via statistical package for social science (SPSS) software 14.0. Twotailed significance level of 0.05 was used to detect significant difference between study variables.

\section{Results}

Twenty (40\%) female and $30(60 \%)$ male were entered to the study. During follow up period five (10\%) patients (four male) were referred to neurosurgeon due to unresponsive to conservative treatment and progressive muscle weakness.

Twenty eight patients (56\%) had Disc Extrusion (DE) and 22 (44\%) patients had Disc herniation (DH). L4- L5 was the most affected level in patients with DE and DH (Table 1).

According to VAS score, pain of patients after six months conservative treatment significantly improves than initial evaluation $(3.11 \pm 1.83,7.1 \pm 1.43 \mathrm{P}=0.00)$ (Table 2).

$\mathrm{DE}$ and DH Patients did not show significant difference in the initial evaluation $(7.42 \pm 1.23,6.68 \pm 1.58 ; \mathrm{P}=0.09)$ and after six months follow up $(2.70 \pm 1.51,3.57 \pm 2.08 ; \mathrm{P}=0.15)$. Male and female patients had no significant difference in mean of VAS in initial (6.83 \pm $1.51,7.50 \pm 1.23 ; \mathrm{P}=0.12)$ and after six months follow up evaluation $(2.88 \pm 1.88,3.42 \pm 1.77 ; \mathrm{P}=0.22)$.

Conservative treatments during six months follow up can significantly improved Oswestry Disability score in study patients $(25.82 \pm 16.92,53.66 \pm 17.66 ; \mathrm{P}=0.00)$ (Table 2).

Mean of Oswestry disability score in DE Patients was significant higher than DH patients in initial evaluation (58.42 $\pm 18.81,47.36$ $\pm 14.17 ; \mathrm{P}=0.03)$ but this significant difference was not seen after conservative treatment during six months follow $(24.91 \pm 14.49,26.85$ $\pm 17.76 ; \mathrm{P}=0.758$ ).

\begin{tabular}{|c|c|c|c|c|c|}
\hline Level & $\mathbf{L}_{3}-\mathbf{L}_{\mathbf{4}}$ & $\mathbf{L}_{\mathbf{4}}-\mathbf{L}_{5}$ & $\mathbf{L}_{\mathbf{5}}-\mathbf{S}_{1}$ & Total \\
\cline { 2 - 5 } & Type of DH & $\mathbf{N}(\%)$ & $\mathbf{N}(\%)$ & $\mathbf{N}(\%)$ & $\mathbf{N}(\%)$ \\
\hline$D H$ & $1(4.5)$ & $14(63.6)$ & $7(31.8)$ & $22(44)$ \\
\hline DE & $1(3.6)$ & $14(50)$ & $13(46.4)$ & $28(56)$ \\
\hline Total & $2(4)$ & $28(56)$ & $20(40)$ & $50(100)$ \\
\hline
\end{tabular}

Abbreviations: DH: Disc Herniation; DE: Disc Extrusion

Table 1: Level of Disc Herniations in our patients.

\begin{tabular}{|c|c|c|}
\hline & VAS change & Oswestry Disability Index Score \\
\hline Baseline & $7.1( \pm 1.43)$ & $53.56 \pm 17.66$ \\
\hline After six months & $3.11( \pm 1.83) p<0.0001$ & $25.88( \pm 16.99) p<0.0001$ \\
\hline
\end{tabular}

Abbreviations: VAS: Visual Analog Scale; ODIS: Oswestry Disability Index Score

Table 2: Change of VAS and ODIS at baseline and after six months of treatment.

Mean of SLR degree in study patients after six months follow up significantly improves in comparison with initial evaluation $(68.22 \pm$ $15.67,43 \pm 11.93 ; \mathrm{P}=0.00)$. $\mathrm{DE}$ patients had no significant difference in mean of SLR degree compared to DH patients in initial (41.25 \pm 10.05 , $43.40 \pm 13.92$; $\mathrm{P}=0.66$ ) and after six months follow up evaluation $(67.91 \pm 14.36,68.57 \pm 17.40 ; \mathrm{P}=0.88)$. Although mean of Oswestry disability score had significant difference between patients of two groups in initial evaluation $(\mathrm{P}=0.032)$. Mean of VAS and SLR degree did not have significant difference between patients with surgical and conservative treatment.

\section{Discussion}

In the present study, all the patients had six months follow up period. Only five patients were referred to neurosurgeon due to unresponsiveness to conservative treatment and progressive muscle weakness. The pain severity (measured by VAS) of patients as one of the patients outcome predictors after six months conservative treatment significantly improved than initial evaluation. Peul et al. [12] who assessed surgery versus prolonged conservative treatment for sciatica in a one year follow up period, reported that pain relief according to VAS and Roland Disability Questionnaire was achieved in the first and 26th week of conservative treatment. This study also demonstrated that the clinical outcomes in the patients with acute lumbar disc herniation who treated conservatively were similar to those who treated surgically after one year follow up period. But the recovery rate and pain relief were faster in the patients who had early surgery [12]. Ahn et al. [13] in their study for comparison of clinical outcomes and natural morphologic changes between sequestered and large central extruded disc herniation which were confirmed by MRI study in 22 patients reported that VAS and Oswestry disability scoring showed a greater change in the sequestrated group than other group. Patients can be treated successfully by conservative treatment. Outcomes in central extruded disc herniation patients seemed to be as good as or of sequestered disc herniation [13]. Owlia et al. in their study on 84 patients with newly exacerbated lumbar radicular pain found that pain relief according to VAS was achieved in $75 \%$ of all the patients with conservative treatment with epidural injection after one month follow up [14]. Pearson et al. in their study reported that discectomy resulted greater improvement in back pain than non operative treatment, and this difference was maintained at two years for all herniation locations and morphologies [15].

Oswestry disability score of patients significantly improved with conservative treatment in the follow up period. There was significant difference between mean of Oswestry disability score in two types of herniation $(\mathrm{DE} \& \mathrm{DH})$ in initial evaluation. On the other hand patients with DE had higher Oswestry disability score than patients with DH. But this significant difference wasn't seen after six months follow up. Our study demonstrated that the DE patients had similar treatment response to conservative treatment with the $\mathrm{DH}$ patients. Ahn et al. [13] and Weinstein et al. [16] in their studies reported significant improvement in the Oswestry Disability Score in acute lumbar disc herniation patients with conservative treatment. Masui et al performed their study on twenty-one lumbar disk herniation patients who were 
treated non-surgically and were followed for a minimum of seven years. They investigated patients' clinical outcomes at the initial, two-year follow up. MRI study showed that clinical outcome did not depend on the size of herniation or the grade of degeneration of the intervertebral disc in the minimum seven-year follow-up [17].

Mean of SLR degree after six months follow up significantly improved than initial evaluation. . Mean of Oswestry disability score had significant difference between patients of conservative treatment and surgery treatment. Despite small number of studied cases and rather short period of follow up, this study are in concordance with the similar studies.

Present study has some limitations. First randomization did not design in our study. Second our follow up period was short for our aim and we must select longer follow up time. Third we assessed the pain and disability by VAS and Oswestry Disability Questionnaires in our patients, other methods maybe show different results. Fourth, the study was restricted to an Iranian population. Fifth, presented study was conducted in a single center rendering the external generalizability of our findings to other countries or centers were uncertain. The favorable outcomes associated with the conservative management in disc herniations should be further confirmed in controlled trials.

\section{Conclusion}

According to the results of our study, conservative treatment in patients with acute lumbar disc herniation causes significant pain relief and disability improvement without any notable side effects. Conservative management with proper patient selection can reduce risk of inappropriate surgery in patients with lumbar disc herniation.

There is no relationship between clinical outcome at the end of six months of conservative treatment and type of disc herniation in the initial evaluation.

In 90 percent of patient with conservative treatment clinical improvement was seen.

Oswestry disability score can be a good prognostication indicator for future surgery operations.

\section{Acknowledgment}

This study was fully supported and funded by Shahid Sadoughi University of Medical Sciences.

\section{References}

1. Cherkin DC, Deyo RA, Loeser JD, Bush T, Waddell G (1994) An international comparison of back surgery rates. Spine (Phila Pa 1976) 19: 1201-1206.

2. van Tulder MW, Koes BW, Bouter LM (1995) A cost-of-illness study of back pain in The Netherlands. Pain 62: 233-240.

3. Hardy R, Ball PA (2004) Treatment of disk disease of the lumbar spine, Youmans Neurological Surgery. ( $5^{\text {th }}$ edn) ed: Winn HR, Saunders.

4. Ropper A, Brown R (2005) Pain in the back, Neck and extremities, Asams and Victor's Principles of Neurology. ed: Ropper A, Brown R, McGraw Hill.

5. Mc Cormick $P$ (2005) Intervertebral discs and radiculopathy. In: Rowland L, Lippincott W (Eds.), Merritt's neurology.

6. Welch WC, Gerszten PC (2002) Alternative strategies for lumbar discectomy: intradiscal electrothermy and nucleoplasty. Neurosurg Focus 13: E7.

7. Rozen D, Grass G (2005) Interventional pain medicine approaches to nonradicular low back pain of internal disc disruption origin. Pain Physician 8: 399-409.

8. Pengel LH, Herbert RD, Maher CG, Refshauge KM (2003) Acute low back pain: systematic review of its prognosis. BMJ 327: 323.

9. Saal JA (1996) Natural history and nonoperative treatment of lumbar disc herniation. Spine (Phila Pa 1976) 21: 2S-9S.

10. Rivest C, Katz JN, Ferrante FM, Jamison RN (1998) Effects of epidural steroid injection on pain due to lumbar spinal stenosis or herniated disks: a prospective study. Arthritis Care Res 11: 291-297.

11. Wang JC, Lin E, Brodke DS, Youssef JA (2002) Epidural injections for the treatment of symptomatic lumbar herniated discs. J Spinal Disord Tech 15: 269-272.

12. Peul WC, van Houwelingen $\mathrm{HC}$, van den Hout WB, Brand R, Eekhof JA, et al. (2007) Surgery versus prolonged conservative treatment for sciatica. N Engl J Med 356: 2245-2256.

13. Ahn SH, Park HW, Byun WM, Ahn MW, Bae JH, et al. (2002) Comparison of clinical outcomes and natural morphologic changes between sequestered and large central extruded disc herniations. Yonsei Med J 43: 283-290.

14. Owlia MB, Salimzadeh A, Alishiri G, Haghighi A (2007) Comparison of two doses of corticosteroid in epidural steroid injection for lumbar radicular pain. Singapore Med J 48: 241-245.

15. Pearson AM, Blood EA, Frymoyer JW, Herkowitz H, Abdu WA, et al. (2008) SPORT lumbar intervertebral disk herniation and back pain: does treatment, location, or morphology matter? Spine (Phila Pa 1976) 33: 428-435.

16. Weinstein JN, Lurie JD, Tosteson TD, Skinner JS, Hanscom B, et al. (2006) Surgical vs nonoperative treatment for lumbar disk herniation: the Spine Patient Outcomes Research Trial (SPORT) observational cohort. JAMA 296: 24512459 .

17. Masui T, Yukawa Y, Nakamura S, Kajino G, Matsubara Y, et al. (2005) Natura history of patients with lumbar disc herniation observed by magnetic resonance imaging for minimum 7 years. J Spinal Disord Tech 18: 121-126. 